Туркулец С. Е, Кононец А. Н.

S. Ye. Turkulets, A. N. Kononets

МИГРАЦИЯ КАК ОСНОВНОЙ СПОСОБ ФОРМИРОВАНИЯ ЦАРСКИМ

ПРАВИТЕЛЬСТВОМ НАСЕЛЕНИЯ И ТРУДОВЫХ РЕСУРСОВ ДАЛЬНЕГО ВОСТОКА (ХІХ - НАЧАЛО ХХ ВВ.)

\title{
MIGRATION AS THE MAIN METHOD OF FORMING THE FAR EAST POPULATION AND LABOR RESOURCES BY THE TSARIST GOVERNMENT (XIX - THE BEGINNING OF XX CENTURIES)
}

Туркулец Светлана Евгеньевна - доктор философских наук, профессор кафедры уголовно-правовых дисциплин Дальневосточного государственного университета путей сообщения (Россия, г. Хабаровск, ул. Серышева, 47), тел. 8(4212)40-74 -78. E-mail: ugpd@rambler.ru.

Ms. Svetlana Ye. Turkulets - PhD in philosophy, Professor of the Department of Criminal Law, the Far Eastern State Transport University (Khabarovsk, Serysheva str. 47), ph. 8(4212)40-74-78. E-mail: ugpd@rambler.ru).

Кононец Анастасия Николаевна - старший преподаватель кафедры уголовно-правовых дисциплин Дальневосточного государственного университета путей сообщения (Россия, г. Хабаровск, ул. Серышева, 47), тел. 8(4212)40-74 -78. E-mail: ugpd@rambler.ru).

Ms. Anastasiya N. Konnets - Senior Lecturer, the Department of Criminal Law, the Far Eastern State Transport University (Khabarovsk, Serysheva str. 47), ph. 8(4212)40-74-78. E-mail: ugpd@rambler.ru).

Аннотация. В статье анализируется процесс формирования населения и трудовых ресурсов на Дальнем Востоке. Особое место в заселении дальневосточных земель всегда имела миграция. В разные годы царское Правительство использовало принудительное и «вольное» переселение для освоения и закрепления восточных земель под своей юрисдикцией.

Summary. The article analyzes the process of formation of the population and labor force in the Far East. Migration has always been important in colonization of the Far Eastern lands. Over the years, the tsarist government used forced and «voluntary» relocation for the development and consolidation of the eastern lands under their jurisdiction.

Ключевые слова: миграция, переселение, колонизация, население, трудовые ресурсы, геополитика, Сибирь, Дальний Восток, факторы, воздействие.

Key words: migration, displacement, colonization, population, labor resources, geopolitics, Siberia, the Far East, the factors, influence.

\section{УДК $325.1+331.55(091)(571.62)$}

Важную роль в формировании населения определенной территории, рынка труда и трудовых ресурсов играют миграционные процессы. Миграция населения - это сложный по природе, формам проявления и последствиям процесс. Отметим, что от интенсивности миграционных процессов зависят значимость изменений, происходящих в различных срезах социальной структуры населения, и изменение в территориальном размещении. Миграция способствует обмену трудовыми навыками и производственным опытом, содействует развитию личности, влияет на семейный состав и половозрастную структуру, непосредственно связана с социальной, отраслевой и профессиональной мобильностью населения [8, 345].

Важно понимать, что в разные исторические периоды государство стремилось увеличить численность населения в слабообжитых регионах страны посредством переселения. Это было характерным для России процессом. В разные исторические периоды на миграционные движения оказывали влияние разные причины (факторы), которые мы рассмотрим более подробно на при- 
мере Дальнего Востока. К рассмотрению выберем XIX - начало XX вв. как период начала активного освоения дальневосточного региона.

Вступая в XX в., Россия из аграрной страны становилась индустриальной, росли города. Огромный размах получил процесс дальнейшего заселения и хозяйственного освоения страны.

Особое место в повышении роли индустриального развития как важнейшего фактора, формирующего население и рынок труда в царское время, стала отмена крепостного права Александром II, что послужило стимулом для развития производительных сил. Поэтому одной из характерных черт данной эпохи был рост городского населения.

Отметим, что после отмены крепостного права преобладающей массой в иммигрантской волне на сибирские земли стали безземельные крестьяне, искавшие лучшей доли на свободных землях. Однако Сибирь отнюдь не стала для них той землей свободы и изобилия, достичь которой они стремились, уходя от крепостнического режима в Европейской России.

Следующим важнейшим фактором, влияющим на формирование населения и рынка труда, явилось государственное переселение, тесно связанное с геополитическими интересами освоения восточной территории царской России.

Централизация государственной системы Российской Империи была нацелена на создание единой военной мощи. Причинами этого стало, в первую очередь, уязвимое геополитическое положение - на обширной равнине при почти полном отсутствии естественных преград (горные хребты или морские побережья) провоцировало постоянные попытки захвата и грабежа русских земель со всех сторон, исключая северную.

Процесс интенсивного освоения новых земель за Уральским хребтом и, вследствие этого, включения в народнохозяйственный оборот больших объемов природных ресурсов способствовал массовой миграции в эти районы.

После строительства Транссибирской железной дороги в начале XX в., важно отметить, происходит наибольший приток мигрантов, формирующих население и рынок труда царской России. Если землепроходцы XVII - XVIII вв. следовали за пушниной на север Сибири, то в XIX - XX вв. произошло сельскохозяйственное заселение наиболее плодородных южных районов, степных и лесостепных.

Процесс формирования населения в Сибири и на Дальнем Востоке невозможно рассматривать отдельно, т.к. только освоив Сибирь и развив там экономическую базу, можно было решать вопросы закрепления Дальнего Востока за Российской державой.

Как отмечает И. С. Метелев, власти неоднократно пытались принудить крестьян и ремесленников из Европейской части России посредством административных мер к переселению на Дальний Восток. Объяснить повышенное внимание правительства именно к этим категориям населения можно следующим обстоятельством: требовалось спешно организовать обеспечение первых колонистов всем необходимым, особенно продовольствием. До середины XIX в. Сибирь колонизовалась преимущественно подневольным (принудительным) способом, т.к. способ «вольной» колонизации был для царского правительства неприемлемым. Речь идет, в первую очередь, о высоких затратах, а во вторую - о несвободном в то время положении крестьян [2].

Сельскохозяйственное освоение Сибири начинается в широких масштабах с XIX в. Так, несколько изменилась ситуация с принятием в 1822 г. первого Указа, который позволял переселяться в Сибирь крестьянам всех губерний [7]. Исследователи отмечают, что первое в истории России крупное переселение крестьян - до 400 тыс. человек - было организовано в 1837 - 1859 гг. в Тобольскую, Томскую и Енисейскую губернии.

Следующим важнейшим государственным фактором воздействия на формирование населения и управление трудовыми ресурсами стала политика ссылки неугодных в Сибирь и на Дальний Восток. Осваивая Сибирь, царское Правительство старалось решить еще одну задачу: удалить из центра страны беспокойных и ненадежных в политическом смысле людей. Появилась практика ссылать в сибирские города уголовных преступников (часто вместо смертной казни), участников различных восстаний, происходивших часто по всей России в XVII в., военнопленных. Таким образом, большую часть переселенцев, оказавшихся за Уралом, составили ссыльнокаторжные, со- 
Туркулец С. Е, Кононец А. Н.

МИГРАЦИЯ КАК ОСНОВНОЙ СПОСОБ ФОРМИРОВАНИЯ ЦАРСКИМ ПРАВИТЕЛЬСТВОМ НАСЕЛЕНИЯ И ТРУДОВЫХ

РЕСУРСОВ ДАЛЬНЕГО ВОСТОКА (ХІХ - НАЧАЛО ХХ ВВ.)

средоточившись в наименее заселенных и благоприятных для жизни районах. В XVIII в. в Якутию ссылали старообрядцев и опальных сановников.

Следующим фактором, формирующим население и рынок труда в Сибири и на Дальнем Востоке, можно считать «вольное» переселение. Именно оно стало наиболее массовым способом формирования рынка труда в данных регионах. Хотя трактовка «вольности» достаточна условна, т.к. такое переселение осуществлялось под определенным государственным воздействием и регулированием [3].

Во внутренней политике царского правительства России важно отметить «Временные правила о переселении крестьян на свободные казенные земли» 1881 г. В период 1889 - 1891 гг. разрешение на переселение получили 9,6 тыс. семей, а переселилось в Сибирь свыше 36 тыс. семей [5].

В 1889 г. появился Закон «О добровольном переселении сельских обывателей и мещан на казенные земли», в котором говорилось о льготах и помощи переселенцам, и выполнялся который чисто формально [6].

В 1896 г. начался самый грандиозный миграционный проект дореволюционной России по заселению Сибири. Было создано миграционное Переселенческое управление для оказания содействия заселению и освоению Сибири - казна взяла на себя большую часть расходов по переезду и обустройству. (1885 - 1896 гг. - 165 тыс. переселенцев, 1896 - 1900 гг. - 900 тыс., 1906 - 1914 гг. 4 млн).

С принятием в 1904 г. нового Закона о переселении под названием «Временные правила о добровольном переселении сельских обывателей и мещан-земледельцев» были определены две категории переселенцев, имеющие право на льготы: занимающиеся хлебопашеством и желающие идти в районы, заселение которых выгодно правительству; крестьяне из малоземельных губерний.

В период крестьянского движения 1905 - 1906 гг. состоялся первый съезд уполномоченных дворянских обществ двадцати девяти губерний, составивший «Основные положения по аграрному вопросу», впоследствии ставшие основой новой переселенческой политики царского правительства. Указ от 9 ноября 1906 г. вместе с ликвидацией общинного землевладения поощрял переселение малоземельных и безземельных крестьян в Сибирь. В этом же году началась активная пропаганда переселения путем распространения среди крестьян более 6,5 млн брошюр и листков, 130 тыс. справочных книжек и 400 тыс. разъяснений, касающихся порядка переселений и устройства на государственных землях азиатской части России.

Уже за 10 месяцев 1906 г. за Урал переехало около 113 тыс. переселенцев и 52 тыс. ходоков из Европейской России.

Приведем цифры, отражающие результаты проведения переселенческой политики царского правительства. Всего за период с 1885 по 1915 г., по различным оценкам, переселилось около 5 млн человек зажиточных и др. [5].

Обращаясь к анализу заселения и формирования трудовых ресурсов на Дальнем Востоке, следует отметить, что активное освоение Дальнего Востока из центральных и сибирских регионов началось русскими после быстрого ослабления могущества империи Цин, которая в 1840 г. оказалась втянута в первую опиумную войну. Россия, как и другие государства, приняла активное участие в разделе территорий Цинской империи.

Отметим, что в начале XIX в. ещё не проводились значимые исследования Дальнего Востока. По верхнему течению реки Амур отсутствовало постоянное население (хотя ограничиваться районом Амура на этой территории, конечно, нельзя).

В миграционном движении на Дальний Восток во второй половине XIX - начале XX вв. можно выделить три этапа (см. рис. 1).

В 1860 г. после подписания Пекинского договора Уссурийский край вошел в состав Российской империи (1860 г.). С этого момента началось его активное освоение. Л. Л. Рыбаковский выделяет военную, казачью, промышленную и крестьянскую формы колонизации, используемые в царской России.

Военная колонизация является первоначальной формой заселения Дальнего Востока [4]. Первыми поселенцами на Дальнем Востоке были военнослужащие, которые появились на Амуре и 
Сахалине перед заключением Айгунского договора и сравнительно небольшой численностью несли воинскую службу на постах и в гарнизонах. Власти пытались при помощи льгот, которые предусматривал закон 1893 г., удержать демобилизованных в крае, предполагая, что в случае военных действий эти силы будут нужны. К сожалению, данный способ заселения себя не оправдал. В 1906 г. здесь осталось всего 300 демобилизованных.

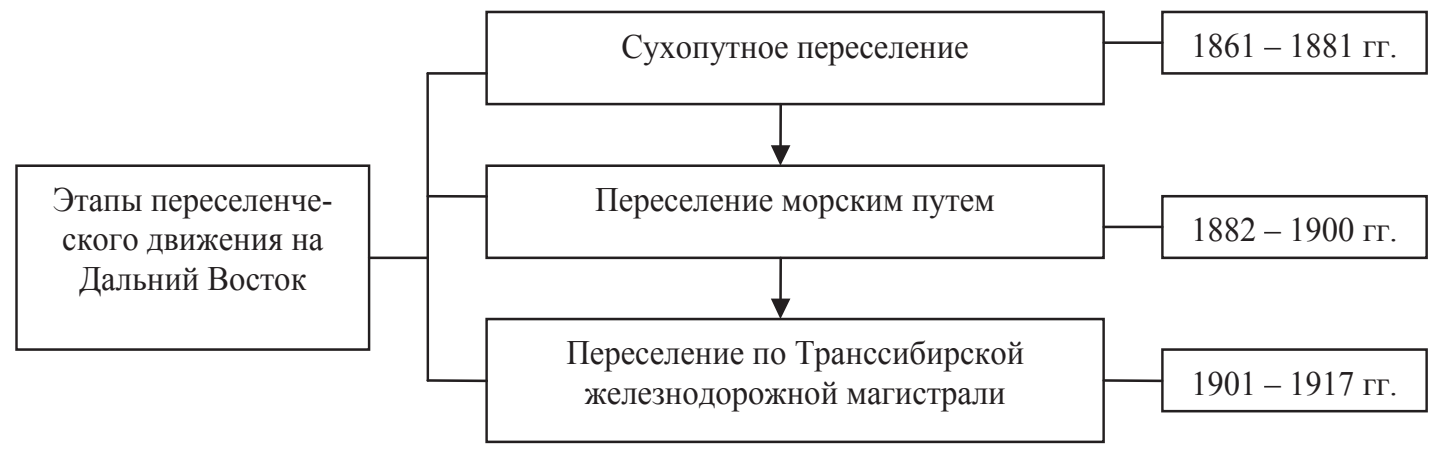

Рис. 1. Этапы переселения на Дальний Восток

В литературе часто встречается мнение о большом вкладе казаков в освоении и заселении дальневосточных территорий. Но освоение казаками не имело большого успеха, т.к. обходилось казне значительно дороже, чем заселение крестьянами. Однако необходимо помнить, что кроме хозяйственного освоения земель, на казаков возлагалась еще одна миссия - их защиты.

Одновременно с этим в Приморье осуществлялось переселение крестьянства и казачества. В частности, колонизация Приморья осуществлялась за счёт переселенцев из европейской части России и Черниговской, Полтавской губерний Украины. Основная заслуга в заселении и освоении южной части края принадлежит украинцам. Они и основали первые населенные пункты: Черниговка, Полтавка, Астраханка и т.д.

Анализ литературы показывает, что промышленная колонизация не являлась основным способом в экономическом освоении Дальнего Востока.

Переселение крестьянства и казачества имело первостепенное значение в миграционном движении на Дальний Восток.

В пореформенный период на Дальний Восток прибыло более 116 тыс. человек, из которых крестьян было 95 тыс. (81,8 \%), а казаков - до 10 тыс. (9 \%). Обратно вернулись не больше 2 \% переселенцев.

В 1897 г. на Дальнем Востоке проживало всего 367 тыс. человек. Отметим, что это территория наиболее позднего хозяйственного освоения и заселения. Во второй половине XIX в. население Дальнего Востока возросло на 68 \% и составило к 1897 г. в Забайкалье - 1071,6 тыс. человек, в Приамурье - 326 тыс. человек, в Приморье, на Камчатке и Сахалине - 540 тыс. человек. То есть за период первоначального капиталистического развития $(1861$ - 1917 гг.) в Приморье и Приамурье было переселено только крестьян 400 тыс. человек. Хозяйственное освоение Дальнего Востока в условиях его малой заселенности, требовало привлечения сюда рабочей силы из других районов страны [1, 38-40].

На начальном этапе колонизация дальневосточного региона имела ряд отличий, которые влияли на формирование дальневосточного социума, на специфику возникновения и развития общественных процессов и явлений внутри него. К отличительным чертам освоения восточных территорий можно отнести следующие:

- необжитость заселяемой земли. Коренные дальневосточные народы были немногочисленными и занимались, главным образом, рыбной ловлей и охотой. Сельскохозяйственной колонизации они не противились;

- заселение края началось в середине XIX в. и по времени было наиболее поздним среди других проводимых Россией колонизаций. Накопленный опыт давал представление о целях и задачах государства в политике колонизации, а также о формах и методах их достижения; 
Туркулец С. Е, Кононец А. Н.

МИГРАЦИЯ КАК ОСНОВНОЙ СПОСОБ ФОРМИРОВАНИЯ ЦАРСКИМ ПРАВИТЕЛЬСТВОМ НАСЕЛЕНИЯ И ТРУДОВЫХ

РЕСУРСОВ ДАЛЬНЕГО ВОСТОКА (ХІХ - НАЧАЛО ХХ ВВ.)

- самое большое значение в царской политике на Дальнем Востоке играл внешнеполитический фактор. Процесс русского заселения восточной территории находился под постоянной угрозой его опережения другими государствами, поэтому царское Правительство России в качестве своей стратегической цели преследовало скорейшее заселение пустующих земель;

- переселенческий процесс приходилось осуществлять на неподготовленные территории в связи с необходимыми ускоренными темпами заселения. Возникающие проблемы решались уже на месте;

- колонизация в аграрной России в большей степени являлась крестьянской, но в ней принимали участие и другие социальные группы: казаки, военнослужащие и ссыльные. Переселенцы, привлекаемые в дальневосточный регион перемещались одним из двух способов: добровольно либо принудительно. Это зависело от тех задач, которые хотела решить власть. По этим причинам отличались и основания перемещения. В дальневосточный регион были допущены и представители сопредельных азиатских стран.

Таким образом, переселенческая политика царского правительства продемонстрировала богатый арсенал примененных средств - от законодательно-нормативных и экономических мер до информационно-пропагандистских мер. Результаты оказались, в целом, положительные: осуществление этой политики дало толчок развитию сельскохозяйственного производства в колонизуемых районах и существенно разгрузило перенаселенные аграрные районы России.

Основной задачей царского Правительства России было освоение и закрепление территории России. В целом перед революцией на практике были опробованы такие методы, как поэтапные переселения (постепенные переселения из одних близ расположенных местностей в другие), выбор предпочтительных районов выхода мигрантов (сходство местностей по природногеографическим и хозяйственным условиям), подбор состава переселенцев (семейных, зажиточных и т.д.).

При этом основная миссия царской России на Дальнем Востоке состояла в решении геополитических задач, стремлении к заселению и хозяйственному освоению новой территории. Очевидным является то факт, что после начала индустриализации на Дальнем Востоке проблемы его слабой заселенности определили и проблемы дефицита трудовых ресурсов. Решить эти проблемы можно было путем привлечения населения. Миграционные потоки, ориентированные на Восток, принесли результаты. Политика государства позволила, таким образом, увеличить население Дальнего Востока во второй половине XIX в. почти на 70 \%.

\section{ЛИТЕРАТУРА}

1. Дальний Восток России: экономическое обозрение / под ред. д.э.н., проф. П. А. Минакира. - 2-е изд., перераб. и доп. - Хабаровск: «РИОТИП», 1995. - 477 с.

2. Метелев, И. С. Формы и методы формирования трудовых ресурсов Сибири и Дальнего Востока: исторический опыт и современность / И. С. Метелев // Проблемы современной экономики. - 2011. - № 4. C. $276-280$.

3. Никитин, Н. И. Освоение Сибири в XVII веке / Н. И. Никитин. - М.: Просвещение, 1990. - 144 с.

4. Рыбаковский, Л. Л. Население Дальнего Востока за 150 лет / Л. Л. Рыбаковский. - М.: Наука, 1990. - 168 с.

5. Хорева, О. Б. Миграционная политика в России: основные этапы, направления, механизмы формирования / О. Б. Хорева // Социальная политика и социальное партнерство. - 2011. - № 9. - С. 54-63.

6. Хорева, О. Б. Управление миграционными процессами в России: история и современность // О. Б. Хорева // Государственная программа по оказанию содействия добровольному переселению в Российскую Федерацию соотечественников, проживающих за рубежом: проблемы и перспективы реализации: материалы науч.-практ. конф., Москва, 20 октября 2009 г. - М.: Проспект, 2010. - С. 183-190.

7. Чиркин, Г. Ф. Очерк колонизации Сибири второй половины XIX в. и начала XX века [Текст] / Г. Ф. Чиркин // Очерки по колонизации Севера и Сибири. - Пг.: Гос. изд., 1922. - 450 с.

8. Юдина, Т. Н. Миграция: словарь основных терминов: учеб. пособие / Т. Н. Юдина. - М.: Изд-во РГСУ, 2007. $-472 \mathrm{c}$. 